\title{
The Function of Interpersonal Communication in Conflict Management Organization
}

\author{
Inge Hutagalung ${ }^{1, *}$ \\ ${ }^{1}$ Postgraduate Communication Programme, Universitas Mercu Buana, Indonesia
}

\begin{abstract}
The research aims to find out how the effectiveness of interpersonal communication functions in conflict management organization. The research results showed that interpersonal communication is taking place can be more effective to make the employee close each other, and creating a favorable climate in the workplace. In organization where a favorable climate is created, the conflict would be solved with deliberation. The conflict is seen as a natural life dynamics and something humane. There are two dimensions of interpersonal communication that is most instrumental in minimizing organizational conflict. The first dimension is the "openness", and the other is the "empathy".
\end{abstract}

\section{Introduction}

Communication functions within the organization are a means to modify behavior, affect change, convey information, and to achieve the goal. "Communication is the lifeblood of an organization" is a phrase that emphasizes that the organization is inseparable from communication. The communication is contributing ideas about how to think and act in the organization. If there is no communication, employees cannot know what is done by other employees, the leadership cannot accept the input of information from his subordinates, and supervisors cannot give instructions to the staff. Coordination of work is not possible and organizations will be disbanded due to lack of communication.

Patterns of communication within the organization can be grouped into two [3], which is a communication network that follows the organizational structure. This communication process flows through formal channels. The second is the communication patterns of informal communication networks. The communication process usually takes place outside formal channels and called grapevine. Informal communication arises from the interaction of individuals with the spread of a message that cannot be suspected, more informal communication leads to interpersonal communication.

*Corresponding author: inge_hutagalung@yahoo.com 


\section{Effectiveness of Interpersonal Communication}

According to the relational perspective view [1], interpersonal communication is defined as that communication occurs between two people who have seen a clear relationship between the two, such as the communication of two brothers, teachers and students, lovers, and others. Because it involves the relationship of two people interacting, then often the interpersonal communication is defined as the dyadic approach.

Dimensions effectiveness of interpersonal communication in a humanistic perspective includes openness, empathy, supportive behavior, and similarity. In general, these properties will help the interaction becomes more effective. Meanwhile, in a pragmatic perspective include self-confidence, togetherness, interaction management, expressive behavior, and orientations to the other party. In this study, researcher used the size of the effectiveness of interpersonal communication with the humanistic approach. The argument was that the humanistic approach in accordance with the conditions of interpersonal communication in an organization.

\section{Research Methodology}

This study used a qualitative approach. Methods of data collection in qualitative research can be done through observation, participation, interviews, and ethnography. The qualitative method is a method that produces descriptive data in the form of words written or spoken by people with observed behavior. Arguments researcher chose a qualitative method is the consideration to be able to adjust to the reality on the ground in an effort to collect data as detailed as possible.

The unit of analysis in this study is a working group within banking organizations, namely the unit front office and back office. As the subjects were selected employees with work restrictions, minimum of two years, starting from the level of the leadership and staff in the unit. The subjects were divided into groups according to the observations of the working structure, composed of 6 unit leaders, 6 front office staff and 6 back office staff. The main data source of this study was obtained through Focus Group Discussion (FGD) through a structured question.

\section{Research Results}

Based on the research results it can be stated that the interpersonal communication contribute to conflict management organization. There are three reasons that can be concluded from the answers of the subjects observations with regard to existing roles, namely (a) the interpersonal communication that exists effectively will produce good relations and cooperation between units in the organization, the clarity of message can be more accountable, the channel to ask or discuss something it is more open; (b) interpersonal communication which take place effectively can make more staff closer to each other, so familiarity could be entwined; (c) the presence of effective interpersonal communication, all disagreements and conflicts can be solved conversationally.

On the other hand, the leader also realize that in business services such as banking, interpersonal communication is very helpful in coordinating and monitoring tasks, build a comfortable working atmosphere, away from the stiffness and boredom. 
The description of the dimensions of the effectiveness of interpersonal communication in the unit of analysis is as follows:

- Openness: The leader always wants to interact with the staff to discuss the issues facing either by phone or face to face. Through the interactions, the staff will know the opinions, thoughts and ideas of the management.

- Empathy: the existence of consciousness of employee that banking is a working system, which means the work unit intertwined in the unity of the organization. Empathy attitude is manifested in the ability and willingness of the employee to put their self in the other person's position or role. If there is a problematic work units then the corresponding work units will help to find suitable solutions

- Supportive behavior: the subject of observation realizing that they really love the organization and have to work in one system according to the vision and mission of the organization. This makes the behavior of individuals who persist in not being an issue.

- Positive behavior: the subject of observation to be positive view of others, self and organizational situations. This positive behavior encourages the employee to communicate openly, relaxed, and friendly to each other.

- Similarity: the subjects of observation had an equivalent position in sending and receiving messages. On the other hand, the dimension of "similarity" also means the employee has the value of communication; attitude; behavior and experience equivalent.

Furthermore, the observation of the subject admits there are two dimensions of interpersonal communication that is most instrumental in minimizing organizational conflict. The first dimension is the "openness". The arguments given were (1) the openness made staff feel comfortable, do not be afraid to ask, while leaders can provide direction and monitor the progress of a given task; (2) openness can be developed through face to face, in writing or using electronic media. The second dimension is empathy. The arguments given were (1) the interpersonal communication can be effective if interpersonal communication can feel and put ourselves in the position of those who communicate; (2) can be a good listener and do not interrupt so that conflict can be avoided.

\section{Discussion}

The organization consists of actions and interactions that involve people. The organization was created and nurtured through continuous interactions change made by people in the organization. The behavior of people in organizations will form organization [5]. In short, communication is a basic human activity. The process of effective communication in an organization will facilitate the operations of the organization, and vice versa, the lack or absence of communication will make the operations of an organization become less successful.

The research results showed that interpersonal communication are interwoven in an effective manner will result in a good cooperation between environmental organizations, the clarity of the message can be more accountable, because the channel to ask questions or discuss something more open. This is in accordance with what is expressed by Robbins [7] that poor communication is most often referred to as the source of the conflicts which ultimately will cause stress and inhibit the performance of the work. Familiarize to 
communicate effectively at work; employees will be able to minimize the stress of work. The same opinion was also expressed by Munandar [2] that an important contribution toward stress management is the quality of the relationship (communication) between the employees or supervisor. Pace [5] also stressed that any difference shape can be muted or minimized by the existence of a supportive climate in order for interpersonal communication can be maintained and improved.

On the other hand, the model of the Dance and Larson [4] can be used to explain how interpersonal communication can minimize conflict within the organization. Through its communication model, Dance and Larson asserts that there are three functions of communication, namely linking function, the function mentation, and regulatory function. If the third communication function is used in an organization then it is seen that the communications function is the center of operational organizations. When employees use communication to connect with other employees (linking function) then the partnership will be realized. Cooperation established will help to achieve the common goal, and generate creative problem solving from a variety of ideas and debate that comes up. The principle of linking function is through an effective communication, togetherness as well as support for the achievement of a common goal can be realized immediately.

As for mentation of the communication function, according to the model of the Dance and Larson can be seen when people communicate to solve complex problems. The more an employee communicating with other people, the more effective problem solving will emerge. Lastly, the regulatory function is the most important part of the communication process in performing the prediction and understanding regulations within an organization to achieve a common goal.

In short, interpersonal communication makes the employees are actively creating the ' world ' in which they can participate and cooperate embodies common goals.

Further, the researcher also assume that the proper functioning of interpersonal communication in minimize conflict also due to cultural factor. According to Ting Toomey [6] in "Communication Across Cultures", cultural in collectivism (as in Indonesia) tend to be goal-oriented groups, using "we" identity, enshrine the obligation in the group rather than personal rights, tend to emphasize the internal relationships of the group, paying more attention to the consideration of the group rather than personal. While an individualism cultural identity "I" (I), more personal, goal-oriented emphasis on personal rights, tend to emphasize the relationships between individuals, paying more attention to personal considerations rather than groups, have a relationship that is voluntary.

Based on the view of collectivism by Ting Toomey, having interpersonal communication effectively in the organization, employees will be able to strengthen the mutual relationship as part of the organization.

\section{Conclusion}

The role of communication within an organization is an absolute. Communication is the blood that turned the organization, the glue that unites all members of the organization, and connecting all systems within the organization. Most of the communication activities carried out in both formal and informal organizations is done through interpersonal communication. Effective interpersonal communication will be very helpful for each employee to be familiar with each other, and to prevent a conflict that would lead to labor conflict. 
There are two dimensions of interpersonal communication that play a dominant role in minimizing labor conflict, namely openness and empathy. Openness, making the employee feels comfortable and appreciated, while the employee can feel empathy create togetherness among employees.

Effective interpersonal communication within the organization will make the conflicts that arise in organization seen as part of the dynamics of the job rather than problems of a personal nature.

\section{References}

1. A. Joseph De Vito, The Interpersonal Communication Book (Harper \& Row Publishers, New York, 1995).

2. Ashar Sunyoto Munandar, Psikologi Industri dan Organisasi (Penerbit Universitas Indonesia, Jakarta, 2001).

3. C. Daniel Fieldman, H.J. Arnold, Managing Individual and Group Behavior in Organization (McGraw Hill International Book Company, Tokyo, 1983).

4. Dance. F.E. X, C.E. Larson, The Functions of Human Communications: A Theoretical Approach (Holt, Rinehart \& Winston, New York, 1976).

5. R. Wayne Pace, F. Faules Don, Komunikasi Organisasi (PT. Remaja Rosdakarya, Bandung, 1998).

6. Stella Ting Toomey, Communicating Across Cultures (The Guildford Press, New York, 1999).

7. Stephen P. Robbins, Organizational Behavior (Prentice Hall, New Jersey, 2001). 